\title{
The Ugi four-component reaction as a concise modular synthetic tool for photo-induced electron transfer donor-anthraquinone dyads
}

\author{
Sarah Bay ${ }^{1}$, Gamall Makhloufi ${ }^{2}$, Christoph Janiak ${ }^{2}$ and Thomas J. J. Müller ${ }^{* 1}$
}

\section{Full Research Paper}

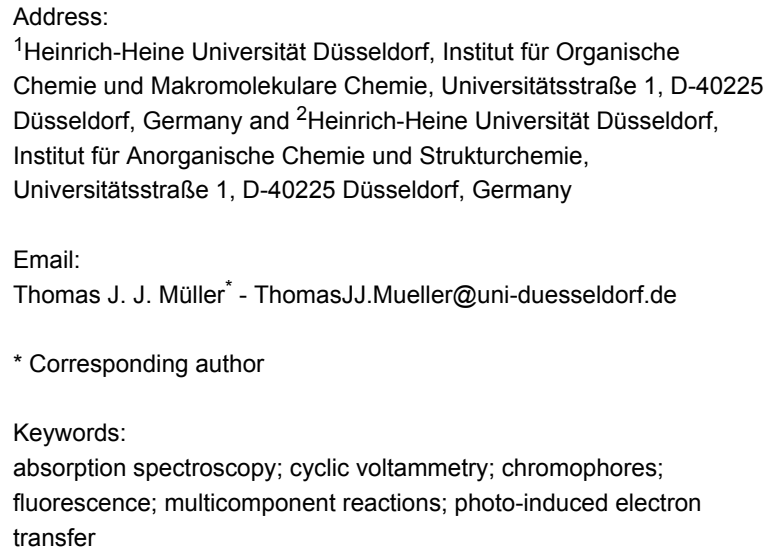

${ }^{1}$ Heinrich-Heine Universität Düsseldorf, Institut für Organische Chemie und Makromolekulare Chemie, Universitätsstraße 1, D-40225 Düsseldorf, Germany and ${ }^{2}$ Heinrich-Heine Universität Düsseldorf, Institut für Anorganische Chemie und Strukturchemie, Universitätsstraße 1, D-40225 Düsseldorf, Germany

Email:

Thomas J. J. Müller ${ }^{*}$ - ThomasJJ.Mueller@uni-duesseldorf.de

* Corresponding author

Keywords:

absorption spectroscopy; cyclic voltammetry; chromophores; fluorescence; multicomponent reactions; photo-induced electron transfer

Beilstein J. Org. Chem. 2014, 10, 1006-1016. doi:10.3762/bjoc. 10.100

Received: 03 February 2014

Accepted: 03 April 2014

Published: 05 May 2014

This article is part of the Thematic Series "Multicomponent reactions II" and is dedicated to Prof. Dr. Christel M. Marian, Heinrich-Heine-Universität Düsseldorf.

Associate Editor: D. Spring

(c) 2014 Bay et al; licensee Beilstein-Institut. License and terms: see end of document.

\begin{abstract}
Phenothiazinyl and carbazolyl-donor moieties can be covalently coupled to an anthraquinone acceptor unit through an Ugi fourcomponent reaction in a rapid, highly convergent fashion and with moderate to good yields. These novel donor-acceptor dyads are electronically decoupled in the electronic ground state according to UV-vis spectroscopy and cyclic voltammetry. However, in the excited state the inherent donor luminescence is efficiently quenched. Previously performed femtosecond spectroscopic measurements account for a rapid exergonic depopulation of the excited singlet states into a charge-separated state. Calculations of the Gibbs energy of photo-induced electron transfer from readily available UV-vis spectroscopic and cyclovoltammetric data applying the Weller approximation enables a quick evaluation of these novel donor-acceptor dyads. In addition, the X-ray structure of a phenothiazinyl-anthraquinone dyad supports short donor-acceptor distances by an intramolecular $\pi$-stacking conformation, an important assumption also implied in the calculations of the Gibbs energies according to the Weller approximation.
\end{abstract}

\section{Introduction}

Chromophores, fluorophores, and electrophores, are functional organic materials [1] and constitute active components in molecular electronics [2], photonics [3], and bioanalytics [4-6]. Therefore, the design of well-defined monomolecular structures with electron-donor (Do) and acceptor (Acc) substitution, so called Do-Acc dyads, is a topical field with a paramount academic and technological interest [7,8]. Tailor-made Do-Acc systems represent the fundamental basis for application in molecular electronics and optoelectronics [9-14] and they are employed in organic light-emitting diodes (OLEDs) for a 
balanced charge transport [15-20] and photovoltaic devices [2125]. The concept of persistent light-induced charge separation between a donor and an acceptor originates from photosynthesis, nature's most important process to convert sunlight into chemical energy. One of the most challenging endeavors of mankind is the unlimited generation of electrical energy from sunlight, with great efforts to mimicking photosynthesis by creation of artificial photosynthetic systems [26,27]. The simulation of relevant processes has reached a high level of understanding and the primary process of light-induced charge separation in various types of Do-Acc dyads has been intensively studied $[28,29]$. This photo-induced electron transfer (PET) [3034] has been investigated with donors such as porphyrines, polycyclic aromatic hydrocarbons, perylenediimides and (oligo)thiophenes [35,36], tetrathiafulvalenes [37], as well as phenothiazine and its derivatives [22,38-40]. The latter have become attractive electrophores due to their reversible and tunable oxidation potential. Interestingly quenching of the phenothiazine inherent fluorescence offers a facile evidence for the occurrence of intramolecular PET in phenothiazinecontaining Do-Acc dyads [41,42]. As suitable acceptor moieties $\mathrm{C}_{60}$ fullerene [43-45], and quinones, such as 9,10anthraquinone as a potential two electron acceptor, have been commonly used in Do-Acc arrangements [46-51]. In previous studies phenothiazine-anthraquinone couples have been introduced into peptide scaffolds [52-54] and rigid Do-Acc dyads [55]. Nevertheless, a modular and rapid access by multicomponent reactions to these types of functional targets has never been explored prior to our recent studies [56]. For instance, the Ugi four-component reaction (Ugi 4CR) [57-60] establishes the chemically robust $\alpha$-aminoacylamide backbone in one step and with high diversity. Therefore, it is also extensively used in medicinal and combinatorial chemistry for lead finding and optimization [61]. We have recently employed the Ugi 4CR as a one-step process to simultaneously introduce a phenothiazinefunctionalized amine and an anthraquinone-substituted aldehyde together with acetic acid and tert-butyl isocyanide for rapidly assembling a donor-acceptor conjugate $\mathbf{1}$ displaying a photo-induced electron transfer leading to a charge-separated state with a lifetime of $>2$ ns (Figure 1), as elucidated by femtosecond transient absorption spectroscopy [56]. The donoronly (2) and acceptor-only (3) models for spectroscopic comparison were obtained analogously.

For enabling rapid accesses to functional $\pi$-systems, such as Do-Acc dyads for photo-induced charge separation, besides a robust, flexible diversity-oriented one-pot reaction, such as the Ugi 4CR, a quick semiquantitative estimation of the feasibility of the charge-separated state based upon inexpensive analytical methods is highly desirable. Here we present the synthetic versatility of this multicomponent approach to Do-anthraquinone dyads, as exemplified by phenothiazinyl and carbazole moieties as donors, and comprehensive physical organic studies of electronic and electrochemical properties investigated by steady state UV-vis and fluorescence spectroscopy as well as cyclic voltammetry. The obtained data are interpreted in the light of the Weller approximation to estimate the probability for charge separation by photo-induced electron transfer based upon its Gibbs energy calculated from the analytical data and donor-acceptor distances of lowest energy conformers from inexpensive force field computations.

\section{Results and Discussion Synthesis and structure}

Within the concept of diversity-oriented syntheses of chromophores [62-69] we have established accesses to chromophores in a one-pot fashion based upon transition metal catalysis as an entry to consecutive multicomponent $[70,71]$ and<smiles>[R]N1c2ccccc2Sc2cc(CN(C(C)=O)C(C(=O)NC(C)(C)C)c3ccc4c(c3)C(=O)c3ccccc3C4=O)ccc21</smiles><smiles>[R]N1c2ccccc2Sc2cc(CN(C(C)=O)C(C)C(=O)NC(C)(C)C)ccc21</smiles><smiles>CC(=O)N(C(C)C)C(C(=O)NC(C)(C)C)c1ccc2c(c1)C(=O)c1ccccc1C2=O</smiles> 
domino reactions [72]. The highly convergent synthetic approach by multicomponent reactions should as well be applicable to functional Do-Acc dyads. Therefore, we set out to place electron-rich phenothiazinyl and carbazolyl derivatives $\mathbf{4}$ as amino component in the Ugi 4CR, whereas the electron acceptor was introduced as anthraquinone-2-carbaldehyde (5) Acetic acid (6) and tert-butyl isocyanide (7) were the two residual components (Scheme 1) [56].

The most favorable solvent for Ugi 4CR is methanol. However, to increase solubility portions of dichloromethane were added to assure a homogeneous solution. For liberating the free base from methylamine hydrochlorides $\mathbf{4}$, potassium hydroxide was employed as a base. The methylamine hydrochlorides $\mathbf{4}$, in turn, were readily available from the corresponding cyano compounds [73] by lithium alanate reduction in diethyl ether [74] The corresponding donor-anthraquinone dyads $\mathbf{8}$ were isolated in moderate to good yields. For reference, donor-only systems 10 were also prepared by Ugi 4CR from the amino derivatives 4 and acetaldehyde (9), in moderate to good yield, with acetic acid (6) and tert-butyl isocyanide (7) as the corresponding acid and isonitrile components (Scheme 2).
The appearance of single signal sets in the ${ }^{1} \mathrm{H}$ and ${ }^{13} \mathrm{C}$ NMR spectra of $\mathbf{8}$ and $\mathbf{1 0}$ unambiguously supports the structural assignment and that isomeric mixtures due to restricted amide-bond rotation can be excluded. Besides mass spectrometry and combustion analysis the structure of phenothiazine-anthraquinone dyads $\mathbf{8 a - d}$ was additionally supported by an X-ray structure analysis of the partially oxidized derivative of compound S(O)-1 (Figure 2) [75]. The phenothiazine and anthraquinone moieties are aligned by intramolecular $\pi$-stacking with an average distance of $\sim 3.9 \AA$ [76,77]. In the unit cell the $R$ - and $S$-enantiomers of a single diastereomer (S-oxide) are arranged in pairs resulting in four stacked (hetero)aromatic units (Figure 2), so that the anthraquinone moieties of two molecules display an average distance of $\sim 3.8 \AA$. Based upon the X-ray data quantum mechanical computations on this conformer were envisioned (vide infra).

\section{Electronic properties and electronic structure}

All dyads $\mathbf{8}$ and $\mathbf{1}$ as well as the reference systems 2, 3, and $\mathbf{1 0}$ were studied by cyclic voltammetry in dichloromethane at room temperature (Table 1, Figure 3).

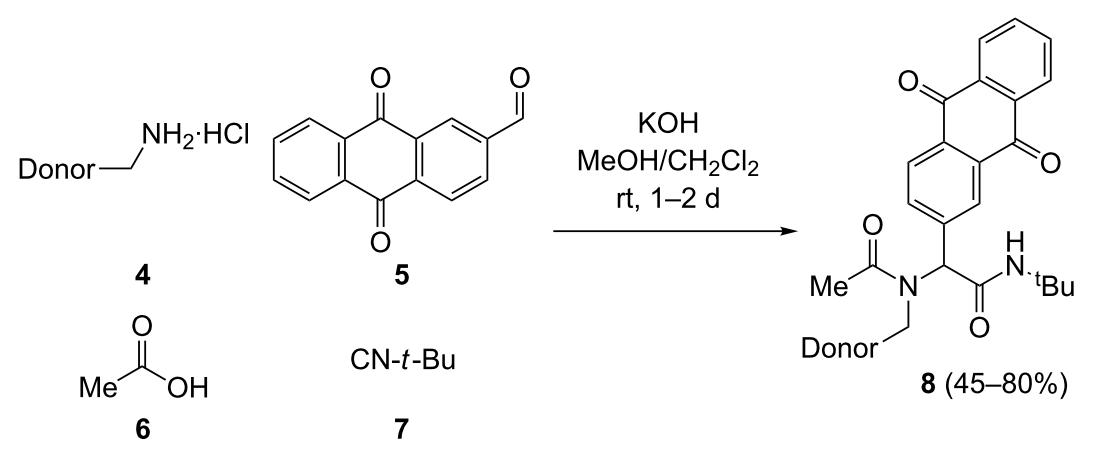

Donor:<smiles>CCCN1c2ccccc2Sc2ccccc21</smiles>

$8 \mathbf{a}(50 \%)$<smiles>Cc1ccc2c(c1)Sc1cc(-c3ccc4c(c3)Sc3ccccc3N4C(=O)O)ccc1N2O[N+](C)([O-])C(C)(C)C</smiles>

$8 d(60 \%)$<smiles>Cc1ccc(CN2c3ccccc3Sc3ccccc32)cc1</smiles>

8 b $(57 \%)$<smiles>Cc1ccc2c(c1)c1ccccc1n2O</smiles>

$8 \mathbf{e}(55 \%)$<smiles>O=[W]N1c2ccccc2Sc2cc(-c3ccc(I)cc3)ccc21</smiles>

$8 c(80 \%)$ 

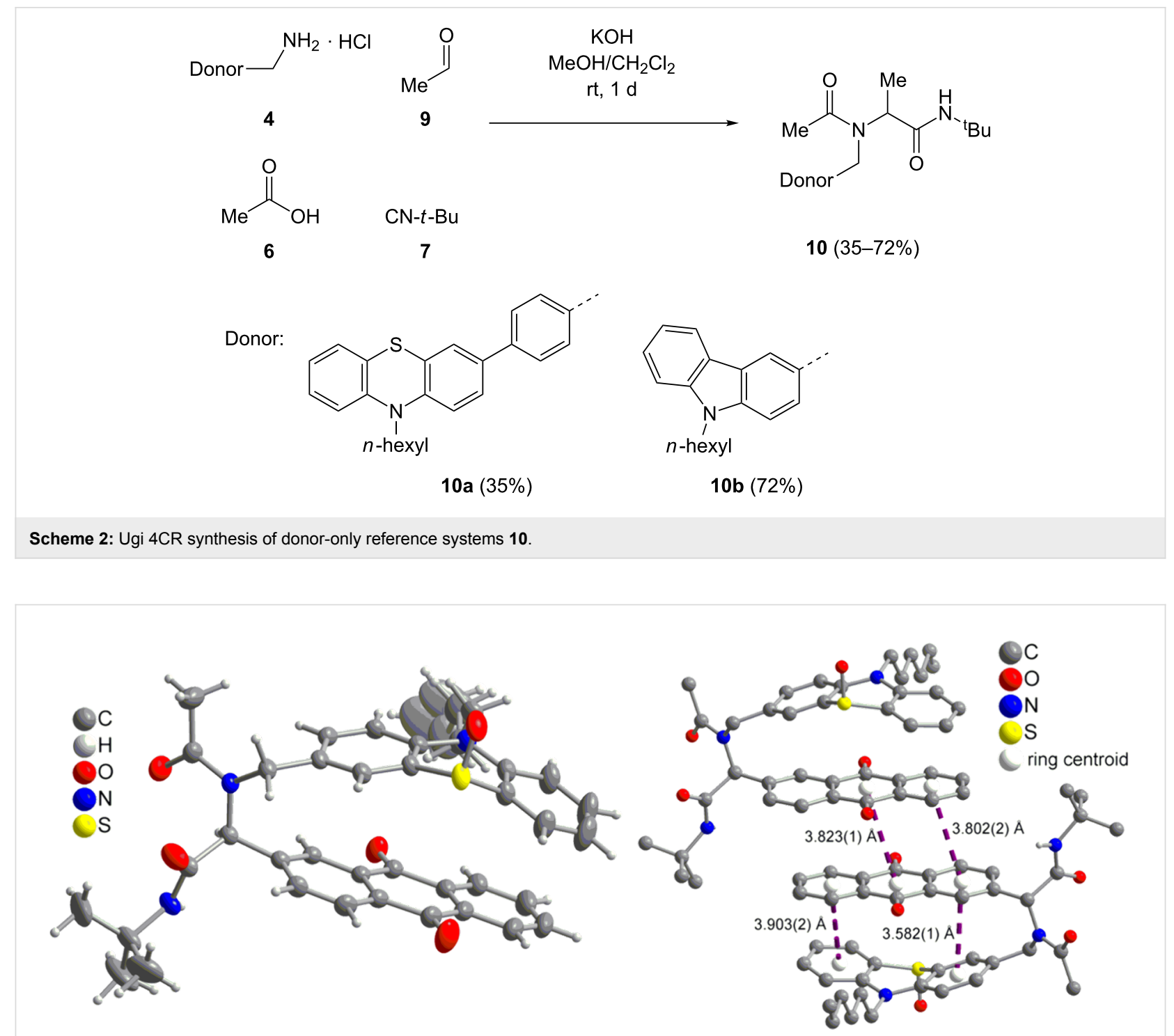

Figure 2: Molecular structure of S(O)-1 (left) (30\% ellipsoids, except for the $\mathrm{CH}_{3} \mathrm{CH}_{2}$ end of the hexyl group, the disordered water molecules were

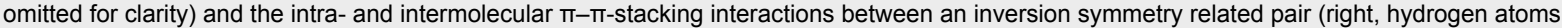
were omitted for clarity).

The cyclic voltammograms were recorded at scan rates $v$ of $100,250,500$ and $1000 \mathrm{mV} \cdot \mathrm{s}^{-1}$ and the differences of anodic and cathodic peak potentials were plotted against $\sqrt{v}$ for extrapolating the half-wave potentials $E_{1 / 2}$ for a scan rate $v=0 \mathrm{mV} \cdot \mathrm{s}^{-1}$ assuming an ideal Nernstian behavior. In the cyclic voltammograms of the phenothiazine-anthraquinone dyads 8a-d, typical for phenothiazine derivatives [41,42,78], first reversible oxidations $E_{1 / 2}{ }^{0 /+1}$ between 630 and $780 \mathrm{mV}$ are found, and in addition the cyclic voltammograms of $\mathbf{8 c}$ and $\mathbf{8 d}$ display second oxidation waves $E_{1 / 2}{ }^{+1 /+2}$ at $1450(\mathbf{8 c})$ and 800 $\mathrm{mV}(\mathbf{8 d})$. The direct comparison of the 3-phenyl derivative $\mathbf{8 c}$ with the donor-only reference $\mathbf{1 0 a}$ clearly indicates that the proximity of the electron-withdrawing anthraquinone moiety does not affect the first and second reversible oxidations of the phenothiazinyl moiety in the Do-Acc dyad 8c. The system 8d containing two conjugated phenothiazinyl moieties is particular since the second oxidation wave originates from the electronic coupling within the diphenothiazine unit $[79,80]$. These values for first and second oxidation can also be found in the donoronly reference compound 10a. Furthermore two quasi-reversible reductions stemming from the anthraquinone core can be detected for $E_{1 / 2}{ }^{-1 / 0}$ between -850 to $-900 \mathrm{mV}$ and for $E_{1 / 2}{ }^{-2 /-1}$ between -1370 and $-1500 \mathrm{mV}$, in good agreement with literature data $[81,82]$. Within a margin of $70 \mathrm{mV}$ both reduction waves fall into the same region as for the anthraquinone-only reference 3 with $E_{1 / 2}{ }^{-1 / 0}$ at $-920 \mathrm{mV}$ and 
Table 1: Cyclovoltammetric data of the dyads 8 and the reference systems 1, 2, 3 and 10 (recorded in $\mathrm{CH}_{2} \mathrm{Cl}_{2}, T=298 \mathrm{~K}$,

$c=0.1 \mathrm{~mol} \cdot \mathrm{L}^{-1}, \mathrm{Pt}$ working electrode, $\mathrm{Pt}$ counter electrode, $\mathrm{Ag} / \mathrm{AgCl}$ reference electrode, electrolyte $\mathrm{N}(n-\mathrm{Bu})_{4} \mathrm{PF}_{6}$, scan rates $v$ of 100,250 , 500 and $\left.1000 \mathrm{mV} \cdot \mathrm{s}^{-1}\right)^{\mathrm{a}, \mathrm{b}}$.

\begin{tabular}{lllll} 
Compound & $\begin{array}{l}E_{1 / 2}{ }^{0 /+1} \\
{[\mathrm{mV}]}\end{array}$ & $\begin{array}{l}E_{1 / 2}^{+1 /+2} \\
{[\mathrm{mV}]}\end{array}$ & $\begin{array}{l}E_{1 / 2}{ }^{-1 / 0} \\
{[\mathrm{mV}]}\end{array}$ & $\begin{array}{l}E_{1 / 2}{ }^{-2 /-1} \\
{[\mathrm{mV}]}\end{array}$ \\
\hline $\mathbf{8 a}$ & 780 & - & $-850^{\mathrm{c}}$ & $-1500^{\mathrm{c}}$ \\
$\mathbf{8 b}$ & 780 & - & $-870^{\mathrm{c}}$ & $-1370^{\mathrm{c}}$ \\
$\mathbf{8 c}$ & 710 & 1450 & $-900^{\mathrm{c}}$ & $-1390^{\mathrm{c}}$ \\
$\mathbf{8 d}$ & 630 & 800 & $-880^{\mathrm{c}}$ & $-1380^{\mathrm{c}}$ \\
$\mathbf{8 e}$ & $1220^{\mathrm{c}}$ & - & $-940^{\mathrm{c}}$ & $-1420^{\mathrm{c}}$ \\
$\mathbf{8 f}$ & $1170^{\mathrm{c}}$ & - & $-920^{\mathrm{c}}$ & - \\
$\mathbf{1}$ & 710 & - & $-870^{\mathrm{c}}$ & $-1430^{\mathrm{c}}$ \\
$\mathbf{3}$ & - & - & $-920^{\mathrm{c}}$ & $-1430^{\mathrm{c}}$ \\
$\mathbf{2}$ & 730 & - & - & - \\
$\mathbf{1 0 a}$ & 710 & 1430 & - & - \\
$\mathbf{1 0 b}$ & $1320^{\mathrm{c}}$ & - & - & - \\
\hline
\end{tabular}

aCalibrated against ferrocene as an internal standard $\left(E_{0}{ }^{0 /+1}=\right.$ $450 \mathrm{mV}$ ). ${ }^{\mathrm{b}}$ The half-wave potentials $E_{1 / 2}$ were extrapolated to a scan rate of $v=0 \mathrm{mV} \cdot \mathrm{s}^{-1}$ from the linear correlation plot of the differences of the anodic and cathodic peak potentials against $\sqrt{v}$. 'Quasi-reversible redox wave.

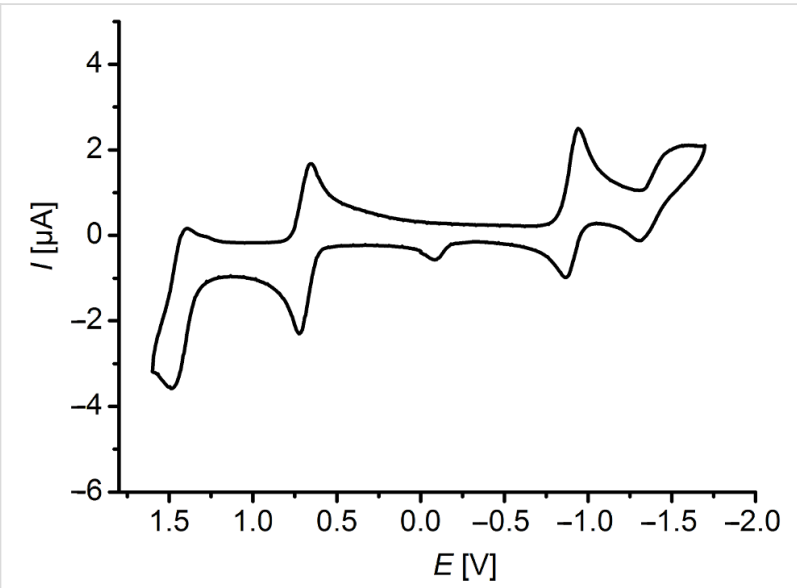

Figure 3: Cyclic voltammogram of dyad $8 \mathrm{c}$ (recorded in $\mathrm{CH}_{2} \mathrm{Cl}_{2}, T=$ $298 \mathrm{~K}, c(8 \mathrm{c})=0.1 \mathrm{~mol} \cdot \mathrm{L}^{-1}$, $\mathrm{Pt}$ working electrode, $\mathrm{Pt}$ counter electrode, $\mathrm{Ag} / \mathrm{AgCl}$ reference electrode, electrolyte $\mathrm{N}(n-\mathrm{Bu})_{4} \mathrm{PF}_{6}$, scan rate of 250 $\left.\mathrm{mV} \cdot \mathrm{s}^{-1}\right)$

$E_{1 / 2}{ }^{-2 /-1}$ at $-1430 \mathrm{mV}$. Cum grano salis the electrochemical behavior of the novel dyads $\mathbf{8 a}-\mathbf{d}$ are very similar to the parent system 1. The carbazole-based dyads $\mathbf{8 e}$ and $\mathbf{8 f}$ only show quasi-reversible oxidation waves at an estimated $E_{1 / 2}{ }^{0 /+1}$ of 1220 and $1170 \mathrm{mV}$, yet in good agreement with the behavior of the carbazole-only reference $\mathbf{1 0 b}$ with an estimated $E_{1 / 2}{ }^{0 /+1}$ at $1320 \mathrm{mV}$. The carbazole-anthraquinone dyads 8e and $8 \mathbf{f}$ display the anthraquinone-centered first quasi-reversible reduction wave $E_{1 / 2}{ }^{-1 / 0}$ at $-940(\mathbf{8 e})$ and $-920 \mathrm{mV}(\mathbf{8 f})$, the second quasi-reversible reduction wave is only found for dyad $\mathbf{8 e}$ and appears at $E_{1 / 2}-2 /-1=-1420 \mathrm{mV}$. The comparison of the cyclic voltammograms between all dyads $\mathbf{8}$ and the reference systems $\mathbf{2}, \mathbf{3}$, and $\mathbf{1 0}$ clearly shows that the donor and anthraquinone moieties are essentially electronically decoupled in the electronic ground state. Therefore, in the electronic ground state the electronic effects should behave additively, i.e., as if the donors and anthraquinones were placed at large distances.

Based on the starting geometry from the X-ray structure analysis of $\mathrm{S}(\mathrm{O}) \mathbf{- 1}$ the frontier molecular orbitals (FMO) of $\mathbf{1}$ were calculated on the DFT level of theory with the B3LYP functional and the Pople basis set 6-311G* (Figure 4) [83-86]. It is noticeable that the coefficient density of the HOMO is almost completely localized on the phenothiazine unit whereas the coefficient density of the LUMO resides on the anthraquinone core, supporting the electronic decoupling of the donor and the acceptor in the electronic ground state. In conclusion the computation underlines that in dyad $\mathbf{1}$ an electronic prerequisite for electronically favored electron-transfer processes in donor-acceptor systems is the spatial proximity of PT and AQ. This conformer is additionally stabilized by $\pi$-stacking of the donor and the acceptor, which is adopted in the solid state and results in a strong bathochromically shifted absorption of the solid.
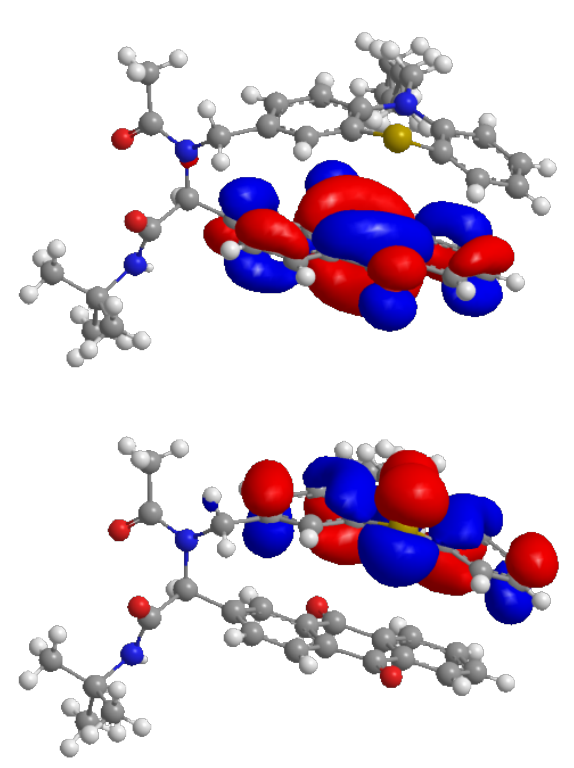

Figure 4: DFT-computed (B3LYP, 6-311G*) frontier molecular orbitals HOMO (bottom) and LUMO (top) of the phenothiazine-anthraquinone dyad 1.

Furthermore, the electronic properties of the donoranthraquinone dyads $\mathbf{8}$ were studied by absorption and emission spectroscopy (Table 2). All phenothiazine-based dyads 8a-d show very similar absorption characteristics with a major 
Table 2: Absorption and emission characteristics of the dyads 8, 1, and the reference systems 2, 3, and $10\left(\right.$ recorded in $\mathrm{CH}_{2} \mathrm{Cl}_{2}$ $\left.c=1.4-3.1 \cdot 10^{-5} \mathrm{~mol} \cdot \mathrm{L}^{-1}, T=298 \mathrm{~K}\right)$.

\begin{tabular}{|c|c|c|c|}
\hline Compound & $\begin{array}{l}\text { Absorption } \\
\lambda_{\max , \mathrm{abs}}[\mathrm{nm}]\left(\varepsilon\left[\mathrm{L} \cdot \mathrm{mol} \cdot \mathrm{cm}^{-1}\right]\right)\end{array}$ & $\begin{array}{l}\text { Emission } \\
\lambda_{\max , \mathrm{em}}[\mathrm{nm}]\end{array}$ & $\begin{array}{l}\text { Stokes shift } \\
\Delta \tilde{v}\left[\mathrm{~cm}^{-1}\right]^{a}\end{array}$ \\
\hline $8 a$ & 257 (44000), 319 (5000) & $-\mathrm{b}$ & - \\
\hline $8 b$ & 258 (87000), 325 (10000) & $-b$ & - \\
\hline $8 c$ & 258 (92000), 326 (19000) & $-\mathrm{b}$ & - \\
\hline $8 d$ & $259(145000), 326(40000)$ & $-b$ & - \\
\hline $8 e$ & 250 (58000), 265 (69000), 298 (21000), 335 (11000) & $-\mathrm{b}$ & - \\
\hline $8 f$ & $255(85000), 285(62000)$ & $-\mathrm{b}$ & - \\
\hline 1 & 258 (69000), 323 (11000) & $-b$ & - \\
\hline 3 & 259 (49000), $329(6000)$ & $-b$ & - \\
\hline 2 & 259 (39000), $311(6000)$ & $450^{c}$ & 9900 \\
\hline $10 a$ & 269 (61000), $320(18000)$ & $463^{d}$ & 9700 \\
\hline $10 \mathrm{~b}$ & 240 (47000), 267 (29000), 298 (17000), 336 (4000), 352 (4000) & $362,377^{e}$ & 800 \\
\hline
\end{tabular}

${ }^{\mathrm{a}} \Delta \tilde{v}=1 / \lambda_{\max , \text { abs }}-1 / \lambda_{\max , \mathrm{em}}\left[\mathrm{cm}^{-1}\right]$. ${ }^{\mathrm{b}}$ The residual fluorescence is only detectable in the base line, i.e., less than $5 \%$ in a.u., vide infra. ${ }^{\mathrm{c}} \lambda_{\mathrm{exc}}=311 \mathrm{~nm} .{ }^{\mathrm{d}} \lambda_{\mathrm{exc}}=320 \mathrm{~nm} .{ }^{\mathrm{e}} \lambda_{\mathrm{exc}}=298 \mathrm{~nm}$.

absorption band around $259 \mathrm{~nm}$ and a lower intensity band around $325 \mathrm{~nm}$ (Figure 5). According to the phenothiazine-only (10a) and anthraquinone-only (3) references phenothiazine as well as anthraquinone absorb in the same region. In the spectrum of the carbazole dyad $\mathbf{8 e}$ the carbazole-typical absorption maxima can be found (cf reference systems 3 and 10b), whereas the spectrum of $\mathbf{8 f}$ displays just two absorption bands at 255 and $285 \mathrm{~nm}$, originating from the 3-phenylcarbazole moiety.

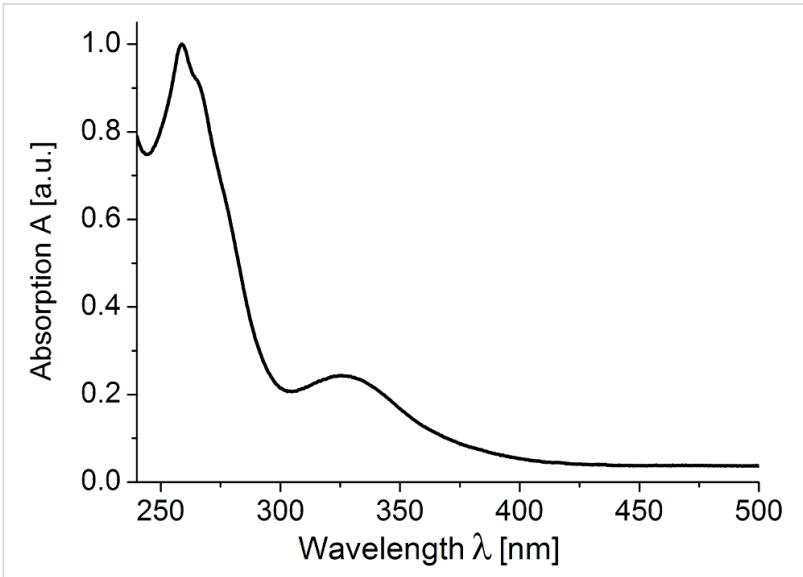

Figure 5: Normalized absorption spectra of the phenothiazine-anthraquinone dyad $8 \mathrm{c}$ (recorded in $\mathrm{CH}_{2} \mathrm{Cl}_{2}$, $\left.c(8 \mathrm{c})=2.5 \cdot 10^{-5} \mathrm{~mol} \cdot \mathrm{L}^{-1}, T=298 \mathrm{~K}\right)$.

The extinction coefficients of the Do-anthraquinone dyads $\mathbf{8}$ are expectedly larger than those of the donor-only (10) or anthraquinone-only (3) compounds. Plotting the extinction coefficient against the wavelength it becomes evident that the Do-anthraquinone dyads behave additively with respect to the constituent reference chromophores (Figure 6). Absorption
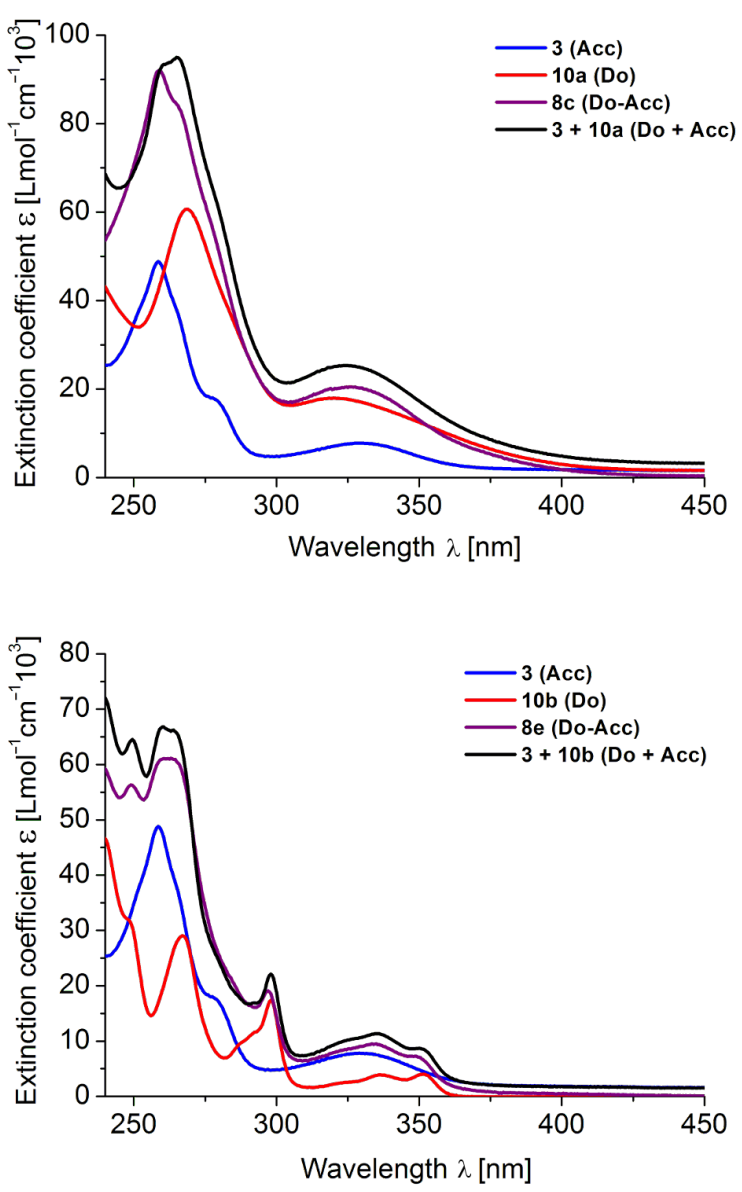

Figure 6: Absorption spectra of Do-anthraquinone dyads 8c (top) and $8 \mathrm{e}$ (bottom) with the corresponding references 3 and $\mathbf{1 0}$, and their addition spectra (Do + Acc) (recorded in $\mathrm{CH}_{2} \mathrm{Cl}_{2}, T=298 \mathrm{~K}$ ). 
spectroscopy as a probe for the electronic ground state also supports that in Do-anthraquinone dyads 8 the donor and anthraquinone moieties are electronically decoupled in the electronic ground state.

Fluorescence is an excited-state phenomenon and, therefore, steady-state emission spectra of the donor-only reference systems $\mathbf{2}$ (Figure 7) and $\mathbf{1 0}$ and the donor-anthraquinone dyads $\mathbf{8}$ were recorded (Figure 8). For the donor-anthraquinone dyads $\mathbf{8}$ the emission is significantly quenched in comparison to the corresponding donor-only model systems $\mathbf{2}$ and $\mathbf{1 0}$ at the same concentrations according to relative fluorescence quantum yields $\Phi_{\text {f,rel }}$ (Table 3 ) and only residual weak emission traces from the donor and/or the anthraquinone excitations can be detected (for spectra of the residual emissions of the dyads $\mathbf{8}$ see Supporting Information File 1). Since the relative fluorescence quantum yields $\Phi_{\mathrm{f}, \text { rel }}$ are attenuated by $95-99 \%$ in comparison to the donors' fluorescence an efficient and rapid nonradiative depopulation of the excited state can be assumed by an electron transfer. This rationale is additionally supported by our previous transient absorption spectroscopic study of the dyad 1 [56].

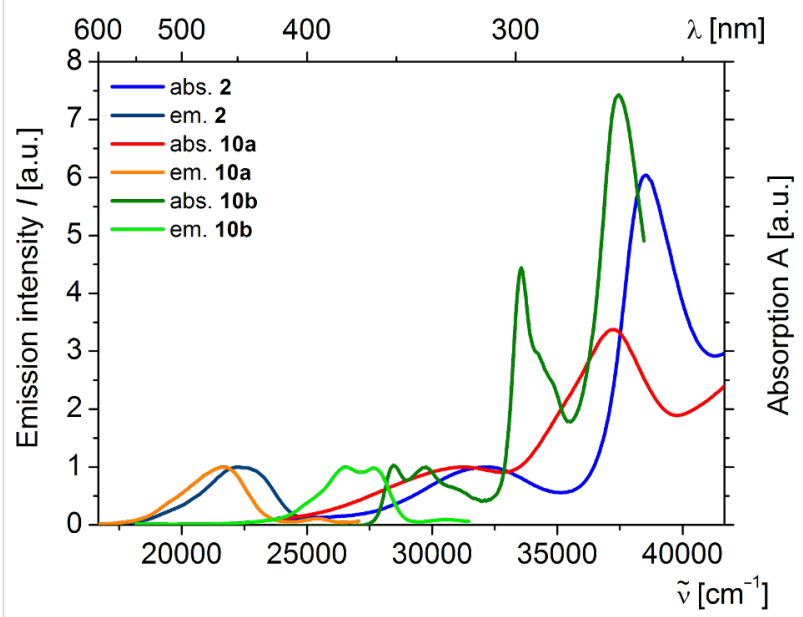

Figure 7: Normalized absorption and emission spectra of Ugi-donor compounds 2 and 10 (recorded in $\mathrm{CH}_{2} \mathrm{Cl}_{2}, T=298 \mathrm{~K}, \lambda_{\max \text {,exc }}(2)=$ $\left.311 \mathrm{~nm}, \lambda_{\max , \operatorname{exc}}(\mathbf{1 0 a})=320 \mathrm{~nm}, \lambda_{\max , \operatorname{exc}}(\mathbf{1 0 b})=298 \mathrm{~nm}\right)$.

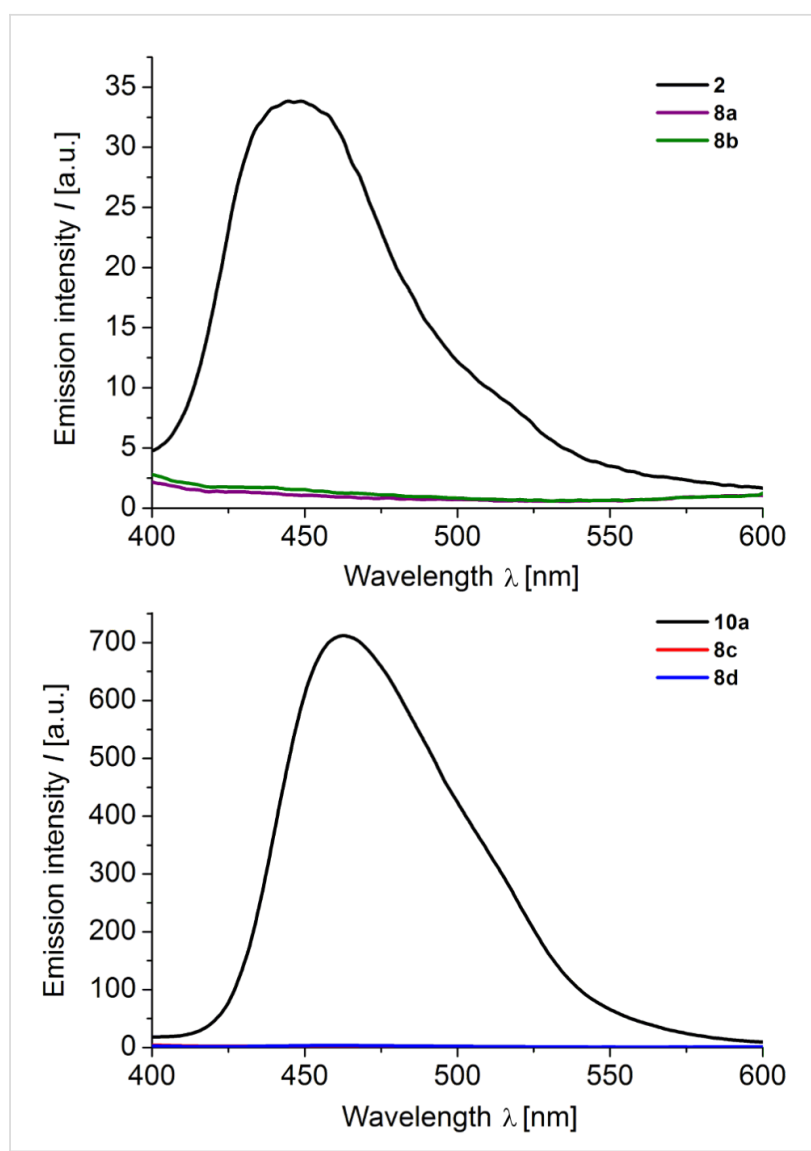

Figure 8: Emission spectra of donor-only system 2 phenothiazine-anthraquinone dyads $\mathbf{8} \mathbf{a}, \mathbf{b}$ (top), and the donor-only system $10 \mathrm{a}$ and the phenothiazine-anthraquinone dyads $\mathbf{8 c}, \mathbf{d}$ (bottom) (recorded in $\mathrm{CH}_{2} \mathrm{Cl}_{2}, T=298 \mathrm{~K}, c=0.7-2.9 \cdot 10^{-6} \mathrm{~mol} \cdot \mathrm{L}^{-1}$ ).

According to the Weller approximation [87] the driving force for a photo-induced electron transfer leading to a charge-separated state that is responsible for the observed fluorescence quenching can be calculated from the measured electrochemical and spectroscopic data. Among several representations for calculating the Gibbs free energy of the electron transfer $\Delta G_{\mathrm{ET}}^{0}$ $[88,89]$ can be described by Equation 1 [90]

$$
\begin{aligned}
& \Delta G_{\mathrm{ET}}^{0}=e\left[E_{\mathrm{ox}}^{0}(\mathrm{Do})-E_{\mathrm{red}}^{0}(\mathrm{Acc})\right]-E_{00}- \\
& \frac{e^{2}}{4 \pi \varepsilon_{0} \varepsilon_{s} R_{\mathrm{Do}-\mathrm{Acc}}}-\frac{e^{2}}{8 \pi \varepsilon_{0}}\left(\frac{1}{r^{+}}+\frac{1}{r^{-}}\right)\left(\frac{1}{\varepsilon_{\mathrm{ref}}}-\frac{1}{\varepsilon_{\mathrm{s}}}\right)
\end{aligned}
$$

\begin{tabular}{|c|c|c|c|c|c|c|}
\hline Donor-only reference & 2 & & $10 a$ & & $10 \mathrm{~b}$ & \\
\hline Donor-anthraquinone dyad & $8 a$ & $8 b$ & $8 c$ & 8d & $8 e$ & $8 f$ \\
\hline$\Phi_{\mathrm{f}, \mathrm{rel}}{ }^{\mathrm{a}}$ & 0.04 & 0.05 & $<0.01$ & $<0.01$ & 0.01 & 0.04 \\
\hline
\end{tabular}

Table 3: Relative quantum yields $\Phi_{\mathrm{f}, \text { rel }}$ of Do-anthraquinone dyads 8 in comparison to their donor-only reference systems 2 and 10.

aDetermined in $\mathrm{CH}_{2} \mathrm{Cl}_{2}, T=298 \mathrm{~K}$, the quantum yield of the corresponding reference was set to 1.0 . 
Where $E_{\mathrm{ox}}^{0}(\mathrm{Do})-E_{\mathrm{red}}^{0}(\mathrm{Acc})$ is the difference of the first oxidation potential of the donor and first reduction potential of the acceptor, respectively, $E_{00}$ expresses the energy of the photonic excitation, $R_{\text {Do-Acc }}$ delineates the distance between the centers of the donor and acceptor moieties, $\varepsilon_{\mathrm{S}}$ and $\varepsilon_{\mathrm{ref}}$ are the dielectric constants of the solvent applied in spectroscopy $\left(\varepsilon_{\mathrm{s}}\right)$ and reference solvent used in electrochemistry $\left(\varepsilon_{\mathrm{ref}}\right)$, and $r^{+}$and $r^{-}$are indicating the effective ionic radii of the donor radical cation and acceptor radical anion, respectively. It is allowed to neglect the forth term, if spectroscopic and electrochemical measurements are performed in the same solvent. Therefore, Equation 1 simplifies to Equation 2 for calculating $\Delta G_{\mathrm{ET}}^{0}$

$$
\Delta G_{\mathrm{ET}}^{0}=e\left[E_{\mathrm{ox}}^{0}(\mathrm{Do})-E_{\mathrm{red}}^{0}(\mathrm{Acc})\right]-E_{00}-\Delta G_{\mathrm{solv}}^{0}
$$

Where the first two terms indicate the free energy of the chargeseparated state calculated from the spectroscopic and electrochemical measurements (in $\mathrm{eV}$ ) and $\Delta G_{\text {solv }}^{0}$ represents the correction term of the solvent polarity and the effect of the distance of the donor and acceptor moieties according to $\Delta G_{\mathrm{solv}}^{0}=\frac{e^{2}}{4 \pi \varepsilon_{0} \varepsilon_{\mathrm{s}} R_{\mathrm{Do}-\mathrm{Acc}}}$.

Indeed, for all Do-anthraquinone dyads $\mathbf{8}$ exergonic Gibbs free energies for the electron transfer are found, both for the simplified free enthalpy $\Delta G_{\mathrm{ET} \text {,simpl, }}$, i.e., the first two terms of Equation 2 , and upon taking solvation into account with the term $\Delta G_{\text {solv }}^{0}$. Therefore, the extent of the thermodynamically favored charge separation by an intramolecular photo-induced electron transfer (PET), plausibly explaining the observed fluorescence quenching, can be easily determined and compared within the series of related dyad systems (Table 4).
The negative free enthalpies of PET are numerically very similar for $\mathbf{8 b}, \mathbf{8 c}, \mathbf{8 e}$, and $\mathbf{8 f}$, however, larger in quantity for dyad 8a and smaller for dyad 8d. A diminishing of the distance between donor and anthraquinone, e.g., by adopting flexible close-contact conformations as for dyad 8a causes an increase in the driving force of the PET. Smaller excitation energies $E_{00}$ and lower oxidation potentials as for the diphenothiazine dyad 8d cause a smaller PET driving force $\Delta G_{\mathrm{ET}}^{0}$. All phenothiazine systems $\mathbf{8 a - d}$ are excited at longer wavelengths, i.e., at lower energies, than the carbazole dyads $8 \mathbf{e}$ and $\mathbf{8 f}$. Eventually, the absorption characteristics of phenothiazine dyads can be more easily red-shifted and, therefore, charge separation by PET should be accessible with visible light by fine-tuning the donor chromophore towards lower HOMO-LUMO gaps.

\section{Conclusion}

The Ugi four-component reaction represents a rapid and excellent modular and diversity-oriented synthesis of donoranthraquinone dyads with various phenothiazine and carbazole model donors. Cyclic voltammetry and UV-vis spectroscopy clearly indicate an electronic decoupling of the donor and the acceptor substituents in the electronic ground state, whereas the emission of the donor moieties is efficiently quenched according to static fluorescence spectroscopy. The observed peculiar fluorescence quenching was previously studied by femtosecond transient absorption spectroscopy of a related model dyad indicating a photo-induced electron transfer (PET) process into a dark, i.e., non-emissive, charge-separated state. The Gibbs free energies of the PET into the charge-separated states are exergonic and can be quickly calculated from absorption and electrochemical data applying the Weller approximation. The concise synthetic concept to donor-acceptor systems is very general, easy to perform and readily expandable to all

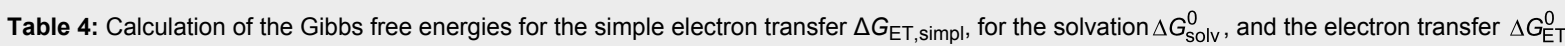
according to the Weller approximation of the dyads $\mathbf{8}$.

\begin{tabular}{|c|c|c|c|c|c|c|}
\hline Compound & $\begin{array}{l}e\left[E_{\text {ox }}^{0}(\mathrm{Do})-E_{\text {red }}^{0}(\mathrm{Acc})\right] \\
{[\mathrm{eV}]^{\mathrm{a}}}\end{array}$ & $\begin{array}{l}E_{00} \\
{[e V]^{b}}\end{array}$ & $\begin{array}{l}\Delta G_{\mathrm{ET}, \text { simpl }} \\
{[\mathrm{eV}]^{\mathrm{c}}}\end{array}$ & $\begin{array}{l}R_{\text {Do-Acc }} \\
{[\mathrm{nm}]^{\mathrm{d}}}\end{array}$ & $\begin{array}{l}\Delta G^{0} \text { solv } \\
{[\mathrm{eV}]}\end{array}$ & $\begin{array}{l}\Delta G^{0} \mathrm{ET} \\
{[\mathrm{eV}]}\end{array}$ \\
\hline $8 a$ & 1.60 & 3.08 & -1.46 & 0.39 & 0.40 & -1.78 \\
\hline $8 b$ & 1.65 & 3.08 & -1.43 & 0.43 & 0.37 & -1.66 \\
\hline $8 c$ & 1.51 & 2.93 & -1.42 & 0.53 & 0.30 & -1.68 \\
\hline $8 d$ & 1.61 & 2.93 & -1.32 & 0.38 & 0.41 & -1.64 \\
\hline $8 e$ & 2.16 & 3.49 & -1.34 & 0.40 & 0.39 & -1.70 \\
\hline $8 f$ & 2.09 & 3.49 & -1.41 & 0.46 & 0.34 & -1.69 \\
\hline
\end{tabular}

aCalculated from $\left(E_{1 / 2}{ }^{0 /+1}-E_{1 / 2}{ }^{-1 / 0}\right)[\mathrm{V}]$ obtained from cyclic voltammetry (see Table 1$) .{ }^{\mathrm{b}} E_{00}[\mathrm{eV}]$ of donor-only reference compounds $2\left(E_{00}=\right.$ $402 \mathrm{~nm}), 10 \mathrm{a}\left(E_{00}=423 \mathrm{~nm}\right)$, and $10 \mathrm{~b}\left(E_{00}=355 \mathrm{~nm}\right)$ were estimated by the intersection of normalized absorption and emission spectra. ${ }^{c} \Delta G_{E T, \text { simpl }}=e\left[E^{0}\right.$ ox $\left.(D o)-E_{\text {red }}^{0}(A c c)\right]-E_{00}$. ${ }^{d}$ The distances $R_{\text {Do-Acc }}[n m]$ of the donor and acceptor centers were estimated from lowest energy conformers by optimized MM2FF calculations [91] taking the distances between the centroid of the anthraquinone and the nitrogen atom of the donor moiety. For the diphenothiazine derivative $\mathbf{8} \mathbf{d}$ the more electron-rich inner phenothiazine was assumed to be oxidized first. 
kinds of functional $\pi$-electron systems. The Weller approximation of the Gibbs free energies of the PET allows a semiquantitative evaluation and optimization of photo-induced charge-separation systems. Studies directed towards multicomponent syntheses of more complex light harvesting and charge separation systems are currently underway.

\section{Experimental}

\section{Synthesis of compounds $\mathbf{8}$ and $\mathbf{1 0}$ via Ugi} four-component reaction (General Procedure) in a manner similar to [56])

In a $25 \mathrm{~mL}$ Schlenk tube $0.50 \mathrm{mmol}$ of the donor hydrochloride 4 and potassium hydroxide $(28 \mathrm{mg}, 0.50 \mathrm{mmol})$ were dissolved in methanol and the mixture was stirred for $30 \mathrm{~min}$ (for experimental details see Table 5). A solution of aldehyde 5 (118 mg, $0.50 \mathrm{mmol})$ in dichloromethane $(2 \mathrm{~mL})$ or the neat aldehyde 9 ( $22 \mathrm{mg}, 0.50 \mathrm{mmol}$ ) were added to the reaction mixture and the solution was stirred at $\mathrm{rt}$ for $1 \mathrm{~h}$, followed by the addition of 1 equiv of acetic acid (6) (30 mg, $0.50 \mathrm{mmol})$ and 1 equiv of tert-butyl isocyanide (7) (42 $\mathrm{mg}, 0.50 \mathrm{mmol}$ ) by syringe. The reaction mixture was stirred overnight at $\mathrm{rt}$. The solvents were removed in vacuo and the crude product was purified by column chromatography on silica gel to give the analytically pure Ugi products $\mathbf{8}$ and $\mathbf{1 0 .}$

\section{Supporting Information}

$$
\begin{aligned}
& \text { Supporting Information File } 1 \\
& { }^{1} \mathrm{H} \text { NMR, }{ }^{13} \mathrm{C} \text { NMR, UV-vis, fluorescence spectra and } \\
& \text { cyclic voltammograms of compounds } \mathbf{8} \text { and } \mathbf{1 0} \text {, a summary } \\
& \text { of the X-ray crystallographic data of S(O)-1, computed } \\
& \text { xyz-coordinates of the structure } \mathbf{1} \text { and HOMO and LUMO } \\
& \text { energies. } \\
& \text { [http://www.beilstein-journals.org/bjoc/content/ } \\
& \text { supplementary/1860-5397-10-100-S1.pdf] }
\end{aligned}
$$

\section{Acknowledgements}

The support of this work by the Fonds der Chemischen Industrie and the Jürgen Manchot Stiftung (scholarship for S. B.) is gratefully acknowledged. The authors also cordially thank M. Sc. Nina Ebert (University of Düsseldorf) for experimental assistance.

\section{References}

1. Müller, T. J. J.; Bunz, U. H. F., Eds. Functional Organic Materials. Syntheses, Strategies, and Applications; Wiley-VCH Verlag $\mathrm{GmbH}$ \& Co. KGaA: Weinheim, Germany, 2007.

2. Müllen, K.; Wegner, G., Eds. Electronic Materials: The Oligomer Approach; Wiley-VCH: Weinheim, Germany, 1998.

3. Müllen, K.; Scherf, U., Eds. Organic Light-Emitting Diodes - Synthesis, Properties, and Applications; Wiley-VCH: Weinheim, Germany, 2006.

4. Kim, E.; Park, S. B. Chem.-Asian J. 2009, 4, 1646-1658. doi:10.1002/asia.200900102

5. Cairo, C. W.; Key, J. A.; Sadek, C. M. Curr. Opin. Chem. Biol. 2010, 14, 57-63. doi:10.1016/j.cbpa.2009.09.032

6. Wagenknecht, H.-A. Ann. N. Y. Acad. Sci. 2008, 1130, 122-130. doi:10.1196/annals.1430.001

7. Petty, M. C.; Bryce, M. R.; Bloor, D., Eds. Introduction to Molecular Electronics; Oxford University Press: New York, USA, 1995.

8. Balzani, V.; Credi, A.; Venturi, M. Molecular Devices and Machines - A Journey into the Nano World; Wiley-VCH: Weinheim, Germany, 2003.

9. Lai, R. Y.; Fabrizio, E. F.; Lu, L.; Jenekhe, S. A.; Bard, A. J. J. Am. Chem. Soc. 2001, 123, 9112-9118. doi:10.1021/ja0102235

10. Armstrong, N. R.; Wightman, R. M.; Gross, E. M. Annu. Rev. Phys. Chem. 2001, 52, 391-422. doi:10.1146/annurev.physchem.52.1.391

11. Richter, M. M. Chem. Rev. 2004, 104, 3003-3036. doi:10.1021/cr020373d

12. Dini, D. Chem. Mater. 2005, 17, 1933-1945. doi:10.1021/cm049567v

13. Kulkarni, A. P.; Wu, P.-T.; Kwon, T. W.; Jenekhe, S. A. J. Phys. Chem. B 2005, 109, 19584-19594. doi:10.1021/jp0529772

\begin{tabular}{|c|c|c|c|c|}
\hline Entry & $\mathrm{MeOH}[\mathrm{mL}]$ & $\mathrm{CH}_{2} \mathrm{Cl}_{2}[\mathrm{~mL}]$ & Reaction time $t[\mathrm{~d}]$ & Ugi 4CR products 8 or 10 (yield) \\
\hline 1 & 3 & 2 & 2 & $153 \mathrm{mg}(50 \%)$ of $8 a$ \\
\hline 2 & 2 & 2 & 1 & $193 \mathrm{mg}(57 \%)$ of $\mathbf{8 b}$ \\
\hline 3 & 2 & 2 & 1 & $299 \mathrm{mg}(80 \%)$ of $8 \mathrm{c}$ \\
\hline 4 & 2 & 2 & 1 & $287 \mathrm{mg}(60 \%)$ of $\mathbf{8 d}$ \\
\hline 5 & 2 & 2.2 & 1 & $187 \mathrm{mg}(55 \%)$ of $8 \mathbf{e}$ \\
\hline 6 & 2 & 2 & 1 & $162 \mathrm{mg}(45 \%)$ of $8 f$ \\
\hline 7 & 3 & - & 1 & $105 \mathrm{mg}(35 \%)$ of $10 a$ \\
\hline 8 & 2 & - & 1 & $162 \mathrm{mg}(72 \%)$ of $10 \mathrm{~b}$ \\
\hline
\end{tabular}

14. Kulkarni, A. P.; Zhu, Y.; Babel, A.; Wu, P.-T.; Jenekhe, S. A. Chem. Mater. 2008, 20, 4212-4223. doi:10.1021/cm7022136

15. Kraft, A.; Grimsdale, A. C.; Holmes, A. B. Angew. Chem., Int. Ed. 1998, 37, 402-428. doi:10.1002/(SICI)1521-3773(19980302)37:4<402::AID-ANIE402>3.0. co;2-9

Table 5: Experimental details for the synthesis of the Ugi products 8 and 10. 
16. Mitschke, U.; Bäuerle, P. J. Mater. Chem. 2000, 10, 1471-1507. doi:10.1039/A908713C

17. Kulkarni, A. P.; Tonzola, C. J.; Babel, A.; Jenekhe, S. A. Chem. Mater. 2004, 16, 4556-4573. doi:10.1021/cm049473।

18. Mishra, A.; Fischer, M. K. R.; Bäuerle, P. Angew. Chem., Int. Ed. 2009, 48, 2474-2499. doi:10.1002/anie.200804709

19. Armstrong, N. R.; Wang, W.; Alloway, D. M.; Placencia, D.; Ratcliff, E.; Brumbach, M. Macromol. Rapid Commun. 2009, 30, 717-731. doi:10.1002/marc.200900075

20. Linton, K. E.; Fisher, A. L.; Pearson, C.; Fox, M. A.; Pålsson, L.-O.; Bryce, M. R.; Petty, M. C. J. Mater. Chem. 2012, 22, 11816-11825. doi:10.1039/c2jm31825c

21. Hoppe, H.; Sariciftci, N. S. J. Mater. Res. 2004, 19, 1924-1945. doi:10.1557/JMR.2004.0252

22. Sun, X.; Liu, Y.; Xu, X.; Yang, C.; Yu, G.; Chen, S.; Zhao, Z.; Quu, W.; Li, Y.; Zhu, D. J. Phys. Chem. B 2005, 109, 10786-10792. doi:10.1021/jp0509515

23. Sonar, P.; Lim, J. P. F.; Chan, K. L. Energy Environ. Sci. 2011, 4, 1558-1574. doi:10.1039/COEE00668H

24. Walker, B.; Kim, C.; Nguyen, T.-Q. Chem. Mater. 2011, 23, 470-482. doi:10.1021/cm102189g

25. Lin, Y.; Li, Y.; Zhan, X. Chem. Soc. Rev. 2012, 41, 4245-4272. doi:10.1039/C2CS15313K

26. McConnell, I.; Li, G.; Brudvig, G. W. Chem. Biol. 2010, 17, 434-447. doi:10.1016/j.chembiol.2010.05.005

27. Alstrum-Acevedo, J. H.; Brennaman, M. K.; Meyer, T. J. Inorg. Chem. 2005, 44, 6802-6827. doi:10.1021/ic050904r

28. Gust, D.; Moore, T. A.; Moore, A. L. Acc. Chem. Res. 2001, 34, 40-48. doi:10.1021/ar9801301

29. Sun, L.; Hammarström, L.; Åkermark, B.; Styring, S. Chem. Soc. Rev. 2001, 30, 36-49. doi:10.1039/A801490F

30. Kavarnos, G. J. Fundamentals of Photoinduced Electron Transfer; Wiley VCH: Weinheim, New York, 1993.

31. Wenger, O. S. Chem. Soc. Rev. 2011, 40, 3538-3550. doi:10.1039/C1CS15044H

32. Lemmetyinen, H.; Tkachenko, N. V.; Efimov, A.; Niemi, M. Phys. Chem. Chem. Phys. 2011, 13, 397-412. doi:10.1039/C0CP01106A

33. Vauthey, E. ChemPhysChem 2012, 13, 2001-2011. doi:10.1002/cphc.201200106

34. Ricks, A. B.; Brown, K. E.; Wenninger, M.; Karlen, S. D.; Berlin, Y. A.; Co, D. T.; Wasielewski, M. R. J. Am. Chem. Soc. 2012, 134, 4581-4588. doi:10.1021/ja205913q

35. Wróbel, D.; Graja, A. Coord. Chem. Rev. 2011, 255, 2555-2577. doi:10.1016/j.ccr.2010.12.026

36. Dössel, L. F.; Kamm, V.; Howard, I. A.; Laquai, F.; Pisula, W.; Feng, X.; Li, C.; Takase, M.; Kudernac, T.; De Feyter, S.; Müllen, K. J. Am. Chem. Soc. 2012, 134, 5876-5886. doi:10.1021/ja211504a

37. Díaz, M. C.; Herranz, M. A.; Illescas, B. M.; Martín, N.; Godbert, N.; Bryce, M. R.; Luo, C.; Swartz, A.; Anderson, G.; Guldi, D. M. J. Org. Chem. 2003, 68, 7711-7721. doi:10.1021/jo034432e

38. Sasaki, Y.; Araki, Y.; Ito, O.; Alam, M. M. Photochem. Photobiol. Sci. 2007, 6, 560-565. doi:10.1039/B617229F

39. Suneesh, C. V.; Gopidas, K. R. J. Phys. Chem. C 2010, 114, 18725-18734. doi:10.1021/jp107606t

40. Li, Z.; Dong, Q.; Li, Y.; Xu, B.; Deng, M.; Pei, J.; Zhang, J.; Chen, F.; Wen, S.; Gao, Y.; Tian, W. J. Mater. Chem. 2011, 21, 2159-2168. doi:10.1039/C0JM02510K

41. Bucci, N.; Müller, T. J. J. Tetrahedron Lett. 2006, 47, 8329-8332. doi:10.1016/j.tetlet.2006.09.075
42. Bucci, N.; Müller, T. J. J. Tetrahedron Lett. 2006, 47, 8323-8327. doi:10.1016/j.tetlet.2006.09.076

43. Imahori, H.; Mori, Y.; Matano, Y. J. Photochem. Photobiol., C 2003, 4, 51-83. doi:10.1016/S1389-5567(03)00004-2

44. Rodríguez-Morgade, M. S.; Plonska-Brzezinska, M. E.; Athans, A. J.; Carbonell, E.; de Miguel, G.; Guldi, D. M.; Echegoyen, L.; Torres, T. J. Am. Chem. Soc. 2009, 131, 10484-10496. doi:10.1021/ja902471w

45. Sandanayaka, A. S. D.; Sasabe, H.; Takata, T.; Ito, O. J. Photochem. Photobiol., C 2010, 11, 73-92. doi:10.1016/j.jphotochemrev.2010.05.001

46. Wasielewski, M. R. Chem. Rev. 1992, 92, 435-461. doi:10.1021/cr00011a005

47. Kurreck, H.; Huber, M. Angew. Chem., Int. Ed. Engl. 1995, 34, 849-866. doi:10.1002/anie.199508491

48. Gouloumis, A.; González-Rodríguez, D.; Vázquez, P.; Torres, T.; Liu, S.; Echegoyen, L.; Ramey, J.; Hug, G. L.; Guldi, D. M. J. Am. Chem. Soc. 2006, 128, 12674-12684. doi:10.1021/ja055344+

49. Wan, J.; Ferreira, A.; Xia, W.; Chow, C. H.; Takechi, K.; Kamat, P. V.; Jones, G., II; Vullev, V. I. J. Photochem. Photobiol., A: Chem. 2008, 197, 364-374. doi:10.1016/j.jphotochem.2008.01.016

50. Kang, Y. K.; lovine, P. M.; Therien, M. J. Coord. Chem. Rev. 2011, 255, 804-824. doi:10.1016/j.ccr.2010.12.011

51. Hankache, J.; Wenger, O. S. Phys. Chem. Chem. Phys. 2012, 14, 2685-2692. doi:10.1039/C2CP23240E

52. McCafferty, D. G.; Bishop, B. M.; Wall, C. G.; Hughes, S. G.; Mecklenburg, S. M.; Meyer, T. J.; Erickson, B. W. Tetrahedron 1995, 51, 1093-1106. doi:10.1016/0040-4020(94)01018-U

53. Striplin, D. R.; Reece, S. Y.; McCafferty, D. G.; Wall, C. G.; Friesen, D. A.; Erickson, B. W.; Meyer, T. J. J. Am. Chem. Soc. 2004, 126, 5282-5291. doi:10.1021/ja0304289

54. Myers, C. P.; Williams, M. E. Coord. Chem. Rev. 2010, 254, 2416-2428. doi:10.1016/j.ccr.2010.02.018

55. Zhang, W.-W.; Mao, W.-L.; Hu, Y.-X.; Tian, Z.-Q.; Wang, Z.-L.; Meng, Q.-J. J. Phys. Chem. A 2009, 113, 9997-10004. doi:10.1021/jp903390v

56. Bay, S.; Villnow, T.; Ryseck, G.; Rai-Constapel, V.; Gilch, P.; Müller, T. J. J. ChemPlusChem 2013, 78, 137-141. doi:10.1002/cplu.201200279

57. Dömling, A.; Ugi, I. Angew. Chem., Int. Ed. 2000, 39, 3168-3210. doi:10.1002/1521-3773(20000915)39:18<3168::AID-ANIE3168>3.0.CO ;2-U

58. Dömling, A. Chem. Rev. 2006, 106, 17-89. doi:10.1021/cr0505728

59. Biggs-Houck, J. E.; Younai, A.; Shaw, J. T. Curr. Opin. Chem. Biol. 2010, 14, 371-382. doi:10.1016/j.cbpa.2010.03.003

60. Qiu, G.; Ding, Q.; Wu, J. Chem. Soc. Rev. 2013, 42, 5257-5269. doi:10.1039/C3CS35507A

61. Dömling, A.; Wang, W.; Wang, K. Chem. Rev. 2012, 112, 3083-3135. doi:10.1021/cr100233r

62. Müller, T. J. J. In Functional Organic Materials. Syntheses, Strategies, and Applications; Müller, T. J. J.; Bunz, U. H. F., Eds.; Wiley-VCH Verlag GmbH \& Co. KGaA: Weinheim, Germany, 2007; pp 179-223.

63. Müller, T. J. J.; D'Souza, D. M. Pure Appl. Chem. 2008, 80, 609-620. doi:10.1351/pac200880030609

64. Yi, C.; Blum, C.; Liu, S.-X.; Frei, G.; Neels, A.; Stoeckli-Evans, H.; Leutwyler, S.; Decurtins, S. Tetrahedron 2008, 64, 9437-9441. doi:10.1016/j.tet.2008.07.084

65. Samanta, A.; Vendrell, M.; Dasa, R.; Chang, Y.-T. Chem. Commun. 2010, 46, 7406-7408. doi:10.1039/C0CC02366C

66. Vendrell, M.; Lee, J.-S.; Chang, Y.-T. Curr. Opin. Chem. Biol. 2010, 14, 383-389. doi:10.1016/j.cbpa.2010.02.020 
67. Main, M.; Snaith, J. S.; Meloni, M. M.; Jauregui, M.; Sykes, D.; Faulkner, S.; Kenwright, A. M. Chem. Commun. 2008, 5212-5214. doi:10.1039/B810083G

68. Briehn, C. A.; Bäuerle, P. Chem. Commun. 2002, 1015-1023. doi:10.1039/B108846G

69. Briehn, C. A.; Schiedel, M.-S.; Bonsen, E. M.; Schuhmann, W.; Bäuerle, P. Angew. Chem., Int. Ed. 2001, 40, 4680-4683. doi:10.1002/1521-3773(20011217)40:24<4680::AID-ANIE4680>3.0.CO ;2-X

70. Willy, B.; Müller, T. J. J. Curr. Org. Chem. 2009, 13, 1777-1790. doi:10.2174/138527209789630479

71. Willy, B.; Müller, T. J. J. ARKIVOC 2008, No. i, 195-208.

72. Müller, T. J. J. Synthesis 2012, 159-174. doi:10.1055/s-0031-1289636

73. Franz, A. W.; Popa, L. N.; Müller, T. J. J. Tetrahedron Lett. 2008, 49, 3300-3303. doi:10.1016/j.tetlet.2008.03.071

74. Mataranga-Popa, L. N.; Franz, A. W.; Bay, S.; Müller, T. J. J. Lett. Org. Chem. 2012, 9, 211-217. doi:10.2174/157017812800167529

75. CCDC 976231 (S(O)-1) contains the supplementary crystallographic data for this paper. This data can be obtained free of charge from The Cambridge Crystallographic Data Centre via http://www.ccdc.cam.ac.uk/data_request/cif.

76. Janiak, C. J. Chem. Soc., Dalton Trans. 2000, 3885-3896. doi:10.1039/B0030100

77. Yang, X.-J.; Drepper, F.; Wu, B.; Sun, W.-H.; Haehnel, W.; Janiak, C. Dalton Trans. 2005, 256-267. doi:10.1039/B414999H And supplementary material therein.

78. Sailer, M.; Nonnenmacher, M.; Oeser, T.; Müller, T. J. J. Eur. J. Org. Chem. 2006, 423-435. doi:10.1002/ejoc.200500539

79. Sailer, M.; Franz, A. W.; Müller, T. J. J. Chem.-Eur. J. 2008, 14, 2602-2614. doi:10.1002/chem.200701341

80. Krämer, C. S.; Zeitler, K.; Müller, T. J. J. Tetrahedron Lett. 2001, 42 , 8619-8624. doi:10.1016/S0040-4039(01)01848-2

81. Gautrot, J. E.; Hodge, P.; Cupertino, D.; Helliwell, M. New J. Chem. 2007, 31, 1585-1593. doi:10.1039/B701257H

82. Li, J.; Kendig, C. E.; Nesterov, E. E. J. Am. Chem. Soc. 2007, 129, 15911-15918. doi:10.1021/ja0748027

83. Gaussian 09, Revision A.02; Gaussian, Inc.: Wallingford, CT, 2009

84. Becke, A. D. J. Chem. Phys. 1993, 98, 5648-5652. doi:10.1063/1.464913

85. Becke, A. D. J. Chem. Phys. 1993, 98, 1372-1377. doi:10.1063/1.464304

86. Parr, R. G.; Yang, W. Density-functional theory of atoms and molecules; Oxford University Press: Oxford, 1989.

87. Weller, A. Z. Phys. Chem. 1982, 133, 93-98.

88. Lor, M.; Viaene, L.; Pilot, R.; Fron, E.; Jordens, S.; Schweitzer, G.; Weil, T.; Müllen, K.; Verhoeven, J. W.; Van der Auweraer, M.; De Schryver, F. C. J. Phys. Chem. B 2004, 108, 10721-10731. doi:10.1021/jp0490352

89. Suzuki, S.; Matsumoto, Y.; Tsubamoto, M.; Sugimura, R.; Kozaki, M.; Kimoto, K.; Iwamura, M.; Nozaki, K.; Senju, N.; Uragami, C.; Hashimoto, H.; Muramatsu, Y.; Konnoe, A.; Okada, K. Phys. Chem. Chem. Phys. 2013, 15, 8088-8094. doi:10.1039/C3CP50182E

90. Berberich, M.; Würthner, F. Chem. Sci. 2012, 3, 2771-2777. doi:10.1039/C2SC20554H

91. SPARTAN '08, V 1.2.0; Wavefunction Inc.: Irvine, CA, 2008.

\section{License and Terms}

This is an Open Access article under the terms of the Creative Commons Attribution License

(http://creativecommons.org/licenses/by/2.0), which permits unrestricted use, distribution, and reproduction in any medium, provided the original work is properly cited.

The license is subject to the Beilstein Journal of Organic Chemistry terms and conditions:

(http://www.beilstein-journals.org/bjoc)

The definitive version of this article is the electronic one which can be found at:

doi:10.3762/bjoc. 10.100 